Article

\title{
Nonlinear Thermopower Behaviour of N-Type Carbon Nanofibres and Their Melt Mixed Polypropylene Composites
}

\author{
Antonio J. Paleo ${ }^{1, *(D)}$, Beate Krause ${ }^{2}\left(\mathbb{D}\right.$, Maria F. Cerqueira ${ }^{3,4}$, Enrique Muñoz ${ }^{5}$, Petra Pötschke ${ }^{2}$ D \\ and Ana M. Rocha ${ }^{1}$
}

check for

updates

Citation: Paleo, A.J.; Krause, B.; Cerqueira, M.F.; Muñoz, E.; Pötschke,

P.; Rocha, A.M. Nonlinear

Thermopower Behaviour of N-Type Carbon Nanofibres and Their Melt Mixed Polypropylene Composites. Polymers 2022, 14, 269. https:// doi.org/10.3390/polym14020269

Academic Editors: Fernão D.

Magalhães, Geoffrey R. Mitchell,

Marta Otero and José António Covas

Received: 8 December 2021

Accepted: 6 January 2022

Published: 10 January 2022

Publisher's Note: MDPI stays neutral with regard to jurisdictional claims in published maps and institutional affiliations.

Copyright: (C) 2022 by the authors. Licensee MDPI, Basel, Switzerland. This article is an open access article distributed under the terms and conditions of the Creative Commons Attribution (CC BY) license (https:// creativecommons.org/licenses/by/ $4.0 /)$.
1 2C2T-Centre for Textile Science and Technology, Campus de Azurém, University of Minho, 4800-058 Guimaraes, Portugal; amrocha@det.uminho.pt

2 Leibniz-Institut für Polymerforschung Dresden e.V. (IPF), Hohe Str. 6, 01069 Dresden, Germany; krause-beate@ipfdd.de (B.K.); poe@ipfdd.de (P.P.)

3 INL-International Iberian Nanotechnology Laboratory, Av. Mestre Jose Veiga, 4715-330 Braga, Portugal; fcerqueira@fisica.uminho.pt

4 CFUM-Center of Physics, Campus de Gualtar, University of Minho, 4710-057 Braga, Portugal

5 Facultad de Física, Pontificia Universidad Católica de Chile, Santiago 7820436, Chile; munoztavera@gmail.com

* Correspondence: ajpaleovieito@2c2t.uminho.pt

\begin{abstract}
The temperature dependent electrical conductivity $\sigma(T)$ and thermopower (Seebeck coefficient) $S(T)$ from $303.15 \mathrm{~K}\left(30^{\circ} \mathrm{C}\right)$ to $373.15 \mathrm{~K}\left(100^{\circ} \mathrm{C}\right)$ of an as-received commercial n-type vapour grown carbon nanofibre $(\mathrm{CNF})$ powder and its melt-mixed polypropylene (PP) composite with 5 wt. $\%$ of $\mathrm{CNF}$ s have been analysed. At $30{ }^{\circ} \mathrm{C}$, the $\sigma$ and $S$ of the $\mathrm{CNF}$ powder are $\sim 136 \mathrm{~S} \mathrm{~m}^{-1}$ and $-5.1 \mu \mathrm{V} \mathrm{K}^{-1}$, respectively, whereas its $\mathrm{PP} / \mathrm{CNF}$ composite showed lower conductivities and less negative S-values of $\sim 15 \mathrm{~S} \mathrm{~m}^{-1}$ and $-3.4 \mu \mathrm{V} \mathrm{K}^{-1}$, respectively. The $\sigma(T)$ of both samples presents a $\mathrm{d} \sigma / \mathrm{d} T<0$ character described by the 3D variable range hopping (VRH) model. In contrast, their $S$ ( $T$ ) shows a $\mathrm{d} S / \mathrm{d} T>0$ character, also observed in some doped multiwall carbon nanotube (MWCNT) mats with nonlinear thermopower behaviour, and explained here from the contribution of impurities in the CNF structure such as oxygen and sulphur, which cause sharply varying and localized states at approximately $0.09 \mathrm{eV}$ above their Fermi energy level $\left(E_{F}\right)$.
\end{abstract}

Keywords: polypropylene; carbon nanofibers; thermoelectric properties; n-type polymer composites; variable range hopping

\section{Introduction}

Thermoelectric (TE) materials are able to transform waste heat into electrical energy. Their efficiency is characterized by the dimensionless figure of merit $z T=\frac{S^{2} \sigma}{k} T$ where the thermopower (Seebeck coefficient) (S), calculated as $S=\Delta V / \Delta T$, reflects the creation of a potential difference $(\Delta V)$ when the ends of a TE material are exposed to a temperature difference, $T$ is the absolute temperature, and $k$ is the thermal conductivity [1,2]. Thereby, $S$ can be positive or negative depending on the type of the majority charge carrier. Hence, in p-type TE materials (positive $S$ ), there is dominant hole conduction, whereas in $\mathrm{n}$ type TE materials (negative $S$ ), the majority of the charge carriers are electrons [3]. In addition, the power factor $\mathrm{PF}=S^{2} \sigma$ is used as a characteristic measure with $\sigma$ as the electrical conductivity [2,4]. Accordingly, materials with large $S$, high $\sigma$ and low $k$ values are necessary for the achievement of high TE properties. In this respect, TE materials based on inorganic materials such as BiTe, SnSe and GeSe are very promising as they show $z T$ values $\geq 1$ [5]. However, the combination of their difficult processibility together with their high cost, partial toxicity, geopolitical risks and poor flexibility have increased interest in searching for different TE materials [6]. In this context, organic materials mainly including conducting polymers (CPs) such as poly(3,4-ethylene dioxythiophene) 
(PEDOT), polyaniline (PANI), polypyrrole (PPy) and their composites have observed fast progress [7]. Moreover, inorganic/organic hybrids, consisting of those electrically conductive polymers and inorganic TE materials, have also attracted great interest $[8,9]$. However, these type of compounds have not yet provided $z T$ s higher than those obtained only with inorganic materials due to the random dispersion of the latter ones in the $\mathrm{CPs}$, as well as the existing divergence of their Fermi energy levels $\left(E_{F}\right)$ [10]. Moreover, the processing in the melt state is more environmentally friendly than in solution as it permits the production of large material volumes with existing equipment and prevents the need of using solvents [11]. Consequently, conductive polymer composites (CPCs), consisting of insulating polymers (IPs) modified with carbon based conductive structures (i.e., carbon black, carbon nanotubes, graphene, etc.), are becoming promising due to the good balance yielded by the flexibility and low $k$ provided by the IP and the high $\sigma$ and $S$ of the carbon materials [6,12]. Among the different types of carbon structures, most attention has focused on the investigation of the TE properties of single-walled carbon nanotubes (SWCNTs) and multi-walled carbon nanotubes (MWCNTs) due to their high $S$ and the possibility of increasing their S-values by different processes [13,14]. Thus, meltmixed composites of polybutylene terephthalate (PBT) with $5 \mathrm{wt} . \%$ SWCNTs have achieved positive $S$ values of $66 \mu \mathrm{V} \mathrm{K}^{-1}$, whereas negative S-values of $-51.5 \mu \mathrm{V} / \mathrm{K}$ have been reported in acrylonitrile butadiene styrene (ABS) composites with $0.5 \mathrm{wt} . \%$ SWCNTs [14]. On the other hand, nitrogen doped MWCNTs always resulted in negative S-values of their composites [15]. Despite the enormous interest in CNTs as novel TE materials mentioned above, very limited efforts have focused recently on the TE properties of a different carbon nanostructure known as carbon nanofibres (CNFs), which typically present larger diameters than CNTs and diverse orientation of the graphitized shells with respect to their hollow tubular axis [16]. This is surprising since early works on heat-treated benzene-derived carbon fibres prepared by thermal decomposition [17], heat-treated graphite fibres grown by pyrolysis of natural gas [18], and heat-treated methane-derived vapor grown carbon fibres (VGCFs) [19], have shown air-stable negative $S$ values at room temperature, contrary to the most as-produced CNTs, which are p-type conductors due to oxygen doping [20]. More recently, a thermopower of $-5.5 \mu \mathrm{V} / \mathrm{K}$ at $30^{\circ} \mathrm{C}$ has been reported for a selected commercial grade of CNFs [21] that additionally showed the benefit of also having air-stable negative S-values. It must be noted that such $n$-type materials are also needed to fabricate effective thermoelectric generators (TEGs) which typically consist of pairs of p-and n-type materials. It is in this context that this study was performed, extending the TE analysis of former works focused on n-type CNFs and their melt-mixed CNF/polypropylene (PP) composites [21,22]. Thereby, in those previous works, the TE properties of n-type CNFs (Pyrograf ${ }^{\circledR}$-III PR 24 LHT XT) and their melt-mixed PP composites with up to $5 \mathrm{wt} . \%$ of $\mathrm{CNFs}$ are analysed and compared exclusively at room temperature. In the present work, the $\sigma(T)$ and $S(T)$ values in the temperature interval from $30^{\circ} \mathrm{C}$ to $100^{\circ} \mathrm{C}$ of a different grade of n-type CNFs (Pyrograf ${ }^{\circledR}$-III PR 19 LHT XT), and their melt-mixed PP/CNF composite with only $5 \mathrm{wt} . \%$ of CNFs are studied, compared and theoretically modelled. To our knowledge, the $S(T)$ of such CNFs and their melt-mixed polymer composites has not been presented before.

\section{Materials and Methods}

\subsection{Material Processing}

A polypropylene powder, Daplen ${ }^{\mathrm{TM}}$ EE002AE (Borealis AG, Vienna, Austria)—a reactor elastomer modified polypropylene intended for injection moulding with a density

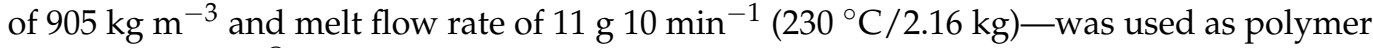
matrix. Pyrograf ${ }^{\circledR}$-III PR 19 LHT XT carbon nanofibres (ASI, Cedarville, OH, EUA) with bulk densities between $1-3 \mathrm{lb} / \mathrm{ft}^{3}\left(0.016-0.048 \mathrm{~g} \mathrm{~cm}^{-3}\right)$ and a range of lengths of 30-100 $\mu \mathrm{m}$ produced by chemical vapour deposition (CVD) were chosen for producing the melt-mixed $\mathrm{PP} / \mathrm{CNF}$ composites. This particular type of $\mathrm{CNF}$ was grown at $1100{ }^{\circ} \mathrm{C}$ with a thermal 
post-treatment at $1500{ }^{\circ} \mathrm{C}$ in inert atmosphere, which morphologically results in a dual wall structure surrounding the hollow tubular core as it is shown in Figure 1.
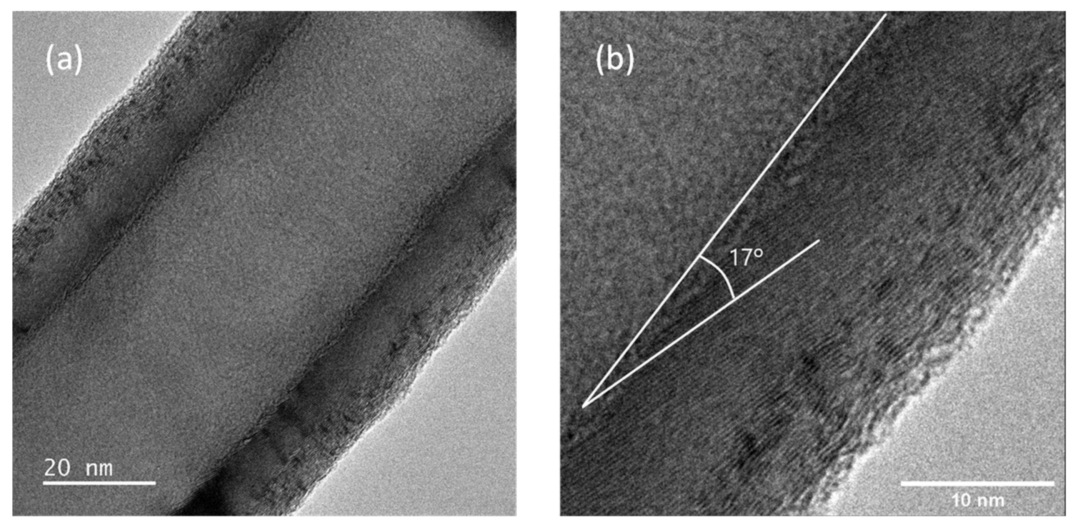

Figure 1. TEM images of vapor grown carbon nanofibres Pyrograf ${ }^{\circledR}$-III PR 19 LHT XT, (a) hollow core and surrounding layers, (b) detail of inner layers constituted of parallel graphene sheets.

Melt-mixed PP/CNF composites were fabricated on a modular lab-scale intermeshing mini-corotating twin-screw extruder, with a screw diameter of $13 \mathrm{~mm}$, barrel length of $338 \mathrm{~mm}$ and an approximate L/D ratio of 26 coupled to a cylindrical rod dye of approximately $2.85 \mathrm{~mm}$ diameter. Further description of the processing conditions has been previously reported [23]. The extruded PP/CNF composites were pelletized and compression-moulded at $210^{\circ} \mathrm{C}$ with a PW40HT hot press for 2 min (1.5 min pre-heating, maximal force $50 \mathrm{kN}, 0.5 \mathrm{~min}$ cooling in a mini-chiller, with a polyimide foil as separator). Circular films with a diameter of $60 \mathrm{~mm}$ and a thickness of $0.5 \mathrm{~mm}$ were prepared for thermoelectric measurements and circular pieces with $12.5 \mathrm{~mm}$ diameter and $1 \mathrm{~mm}$ thickness for thermal conductivity measurements. Based on the electrical conductivity values, in addition to the Pyrograf ${ }^{\circledR}$-III PR 19 LHT XT CNF powder, the melt-mixed PP/CNF composite with 5 wt.\% CNFs (above the electrical percolation threshold [23]) was selected for the morphological, structural and thermopower analysis.

\subsection{TEM, SEM, Raman and XPS Analysis}

The as-received CNFs were observed with a transmission electron microscope (TEM) (JEM-2100, JEOL Ltd., Tokyo, Japan) operating a LaB6 electron gun at $80 \mathrm{kV}$. Images were acquired with an "OneView" $4 \mathrm{k} \times 4 \mathrm{k}$ CCD camera at minimal under-focus to achieve visibility of the CNF surface layers. Extruded strands of the PP/CNF composite were cryo-fractured in liquid nitrogen and the surface was covered with $3 \mathrm{~nm}$ platinum before examining using field emission scanning electron microscopy (SEM) (Ultra plus, Zeiss Oberkochen, Germany) at 3 kV. Raman spectroscopy measurements (ALPHA300 R Confocal Raman Microscope, WITec GmbH, Ulm, Germany) were carried out using $532 \mathrm{~nm}$ laser for excitation in back scattering geometry. The laser beam with $\mathrm{P}=0.5 \mathrm{~mW}$ was focused on the sample by a $50 \times$ lens (Zeiss), and the spectra were collected with 600 groove $/ \mathrm{mm}$ grating using 5 acquisitions with 2 s acquisition time. The surface characterization was performed by means of X-ray photoelectron spectroscopy (XPS) (ESCLAB 250Xi, Thermo Fisher Scientific, Waltham, Massachusetts, EUA) in the ultra-high vacuum (UHV) system. The base pressure in the system was below $5 \times 10^{-10}$ mbar. The XPS spectra were acquired with a hemispherical analyser and X-ray source producing monochromated $\mathrm{Al}$ $\mathrm{K} \alpha(\mathrm{h} v=1486.61 \mathrm{eV})$ radiation operated at $15 \mathrm{kV}$, power $200 \mathrm{~W}$ and $\mathrm{X}$-ray beam spot size $0.65 \mathrm{~mm}$. They were recorded with pass energies of $20 \mathrm{eV}$ and $200 \mathrm{eV}$ for high resolution and survey spectra, respectively. The XPS spectra were peak-fitted using the Avantage processing software (Thermo Fisher Scientific). The Lorentzian/Gaussian (30/70\%) line shape and "Smart" background subtraction were used for peak fitting, and the quantification has been done using sensitivity factors provided by the Avantage library. 


\subsection{Thermoelectric Analysis}

The Seebeck coefficient and volume resistivity of the PP/CNF composite and CNF powder were determined using the self-constructed equipment TEG at Leibniz-IPF [24,25]. The measurements were performed at the mean temperatures of $303.15 \mathrm{~K}\left(30^{\circ} \mathrm{C}\right), 313.15 \mathrm{~K}$, $333.15 \mathrm{~K}, 353.15 \mathrm{~K}$ and $373.15 \mathrm{~K}\left(100{ }^{\circ} \mathrm{C}\right)$, getting the $\mathrm{S}$ values by applying temperature differences between the two copper electrodes up to $\pm 8 \mathrm{~K}$ around the mean temperature in $2 \mathrm{~K}$ steps. The samples were painted with a conductive silver ink at their ends. The measurements of thermovoltage and resistance were performed using a Keithley multimeter (DMM2011, Keithley Instruments, Cleveland, OH, EUA). The volume resistivity was measured at the different mean temperatures using a 4-wire technique. The given values represent the arithmetic mean values of ten measurements. The Seebeck coefficient at each temperature was calculated as the average of eight thermoelectric voltage measurements. For the thermoelectric measurements on the CNF powder, an insert consisting of a PVDF tube (inner diameter $3.8 \mathrm{~mm}$, length $16 \mathrm{~mm}$ ) closed with copper plugs was used, which was filled with the CNF powder [14].

The thermal conductivity of the composites was calculated from the product of thermal diffusivity, density, and specific heat capacity. The thermal diffusivity was measured on circular samples (diameter $12.5 \mathrm{~mm}$, thickness $1 \mathrm{~mm}$ ) through the plate thickness using the light flash apparatus (LFA 447 NanoFlash, Netzsch-Gerätebau GmbH, Selb, Germany) at $303.15 \mathrm{~K}, 313.15 \mathrm{~K}, 333.15 \mathrm{~K}, 353.15 \mathrm{~K}$ and $373.15 \mathrm{~K}$. The specific heat capacity of the composites was calculated by comparing the signal heights between the composite and the reference Pyroceram 9606 (with known specific heat capacity) using the LFA 447 NanoFlash software. The density of the composites was determined using the buoyancy method. The given values represent the mean values of four measurements.

\section{Results and Discussion}

\subsection{TEM, SEM, Raman and XPS Analysis}

Representative TEM images of the used CNFs are shown in Figure 1. The diameter of 25 CNFs was measured and an average diameter of around $110 \mathrm{~nm}$ was obtained. This diameter is comparable to the values measured by Tessonnier et al. for the same type of CNFs [26]. The CNFs show a two-layer structure surrounding the hollow tubular core, where the inner layers present parallel nanosheets with respect to the hollow core. In particular, the inner layers of Figure $1 \mathrm{~b}$ were composed of 29 nanosheets with individual thicknesses of about $0.32 \mathrm{~nm}$ and angles of around $17^{\circ}$ with respect to the main axis of the CNF. Similar nanosheets are also present in the outer layers, though they are not as ordered as in the case of the internal layers. In total, 19 outer graphene sheets with dimensions between 0.32 and $0.35 \mathrm{~nm}$ are observed in Figure 1b. As a conclusion, Figure 1a,b showed two types of morphologies enclosing the hollow tubular core. Moreover, the inner layers seem to be better graphitized than the outer ones.

SEM micrographs related to the PP/CNF composite are shown in Figure 2. The CNFs protrude from the PP and are seen in relatively large length, which is a sign of a low wettability and poor adhesion. This may be due to the not favourable affinity between the nonpolar polyolefin matrix and the CNFs. However, the CNFs seen in Figure $2 b$ indicate $a$ homogenous dispersion and distribution without the presence of agglomerates.

Figure 3 shows the Raman spectra obtained from PP, as-received CNF powder and the $\mathrm{PP} / \mathrm{CNF}$ composite in the range between 600 and $1800 \mathrm{~cm}^{-1}$. Polypropylene shows rich Raman spectra with modes in the range $800-1500 \mathrm{~cm}^{-1}$ [27] assigned to $\mathrm{CH}_{\mathrm{n}}$ stretching vibrations [28]. On the other hand, the as-received CNFs present the two bands expected in carbon nanostructures. One band is found at $1352 \mathrm{~cm}^{-1}$, known as the disordered-induced $\mathrm{D}$ band [29], observable when defects are present in the carbon aromatic structure, and the G-band is found at $1580 \mathrm{~cm}^{-1}$, characteristic of the ideal graphitic lattice vibration [30]. As expected, the PP/CNF composite presents the signatures of the two base materials. In particular, the most intense modes of PP (dotted lines in Figure 3a) are clearly observable in PP/CNF composites. Interestingly, a relative intensity change is observed between the 
two PP peaks located at the vicinity of $800 \mathrm{~cm}^{-1}$, which can be related to the presence of the CNFs in the PP/CNF composite. Moreover, the peak at $1460 \mathrm{~cm}^{-1}$, corresponding to the PP (numbered as 3 in Figure 3a) also shows the same intensity as the G and D bands in the PP/CNF composite, whereas peaks 1 and 2 of the PP hide the D-band of the CNFs in the PP/CNF composite (Figure 3b). These results suggest a strong presence of PP in the analysed area. It is also of note that the $G$ peak for the PP/CNF composite shows an apparent shoulder peak at $\sim 1600 \mathrm{~cm}^{-1}$, which can be associated to the existence of a $\mathrm{D}^{\prime}$ mode caused by defects in the CNFs [31]. The peak position and the full width half maximum (FWHM) of the modes for CNFs and the PP/CNF composite were determined by fitting the Raman spectra with Lorentzian functions, and the obtained parameters are listed in Table 1 together with the in-plane graphitic domain size (La) calculated according to $\mathrm{L}_{\mathrm{a}}(\mathrm{nm})=4.4 /\left(\mathrm{I}_{\mathrm{D}} / \mathrm{I}_{\mathrm{G}}\right)$ [32]. Interestingly, the $\mathrm{FWHM}_{\mathrm{G}}(90)$ and $\mathrm{FWHM}_{\mathrm{D}}(115)$ of the CNF powder are higher than previous values reported for the same type of CNFs [26]. Typically, a decrease in the width of the D and G bands has been associated with an enhancement of the degree of graphitization in CNFs [26]. Notably, the values of $\mathrm{FWHM}_{\mathrm{G}}$ and $\mathrm{FWHM}_{\mathrm{D}}$ decrease clearly in the PP/CNF composites, an observation that has been attributed earlier to the increasing size of remaining agglomerates when enhancing the concentration of CNFs [31]. However, such effect was not observed based on the SEM images shown in Figure 2. Table 1 shows that the $G$ and $D$ peak positions were practically the same and with slightly higher wavenumbers than the CNF powder in the PP/CNF composite. This indicates that the processing did not affect seriously the structure of the as-received CNFs. The intensity ratios between the $\mathrm{D}$ and $\mathrm{G}$ bands $\left(\mathrm{I}_{\mathrm{D}} / \mathrm{I}_{\mathrm{G}}\right)$ were calculated and presented also in Table 1 since they are an important parameter for quantifying the number of disordered (D) and ordered $(G)$ carbon atoms [33]. Notably, the $I_{D} / I_{G}$ of 0.76 for the CNF powder results lower than the value of 1 reported for the same type of CNFs [26]. Moreover, the $\mathrm{I}_{\mathrm{D}} / \mathrm{I}_{\mathrm{G}}$ remains practically the same for the CNF powders and the PP/CNF composites, and, therefore, the production of the PP/CNF composites by melt-mixing did not have a strong effect on this parameter. However, the calculated in-plane graphitic domain size $\mathrm{L}_{\mathrm{a}}$ was slightly higher for the PP/CNF composite. This result agrees with a previous work on melt-mixed PP/CNF composites made with another grade of Pyrograf ${ }^{\circledR}$-III CNFs (PR 24 LHT XT), and it can be explained by the increase of the PP crystallite size caused by the introduction of CNFs [22].
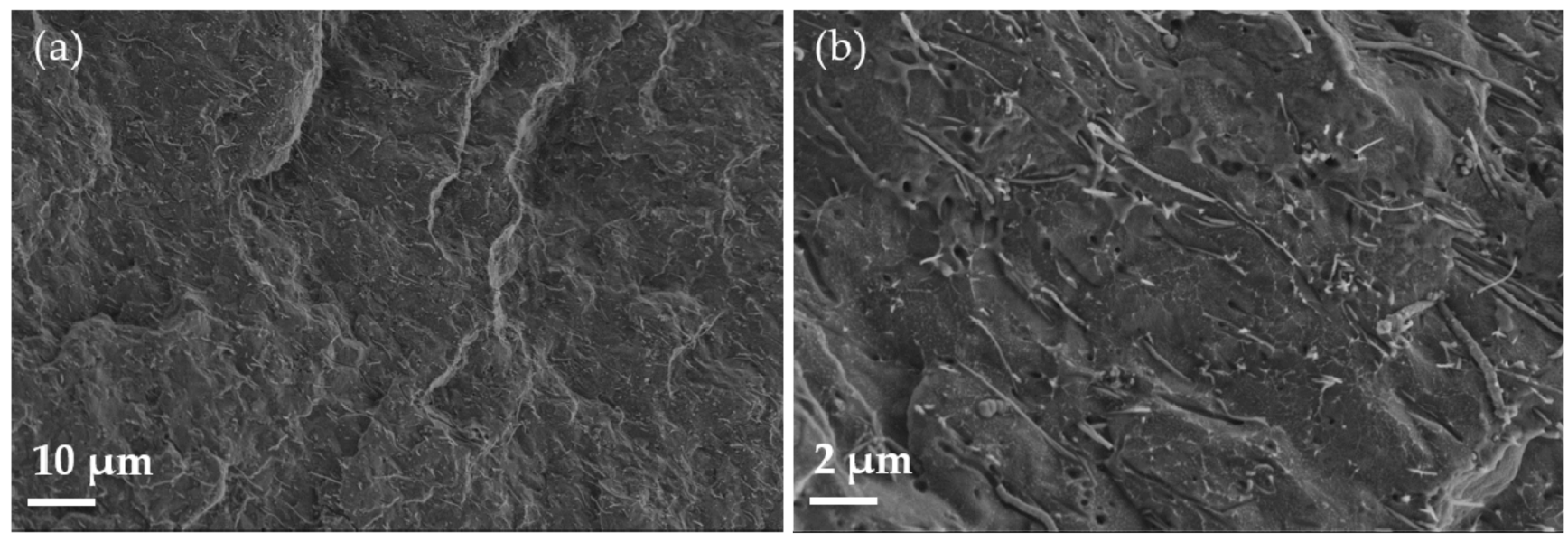

Figure 2. SEM micrographs of the PP/5wt.\% CNF composite at lower (a) and higher (b) magnifications. 

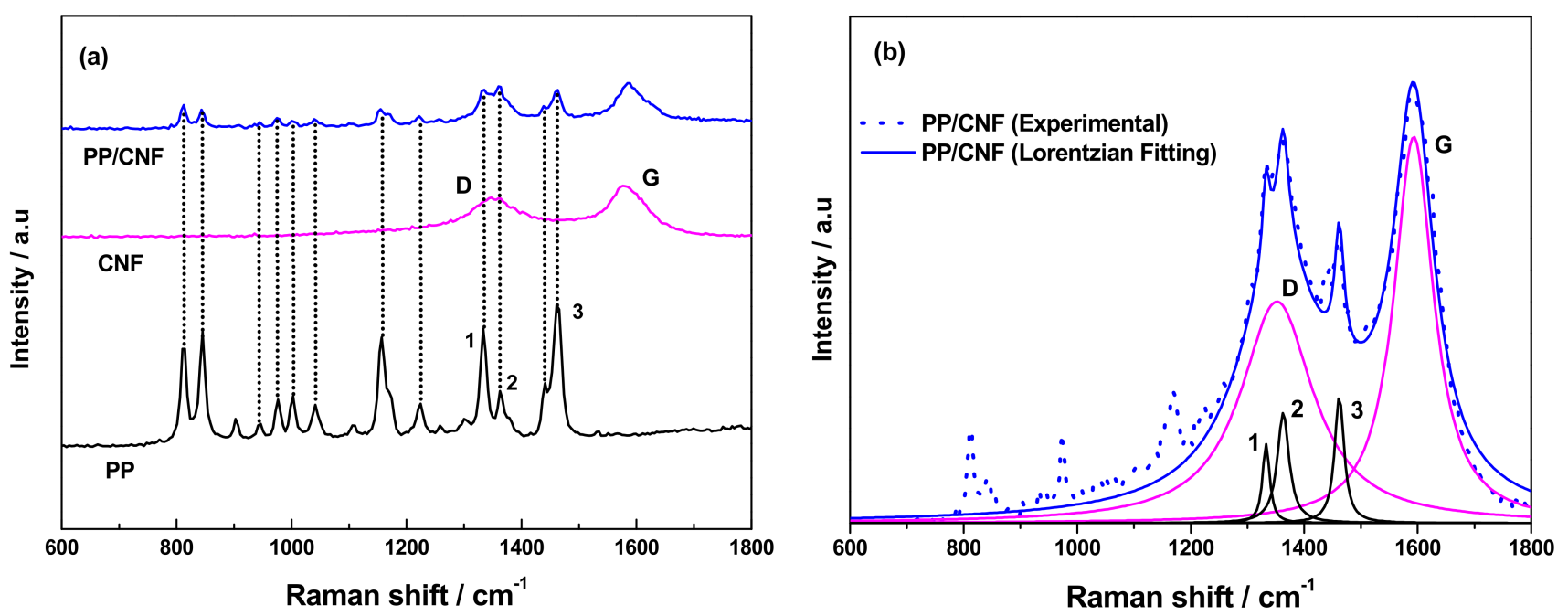

Figure 3. (a) Raman spectra of PP, as-received CNFs and PP/5wt.\% CNF composite. (The dotted lines are to guide the eye), (b) Raman fit in the $\mathrm{G}$ and $\mathrm{D}$ wavenumber range of PP/5wt.\% CNF composite (blue line), showing the different components: CNFs (violet line) and PP (black line).

Table 1. D and G, FWHM, $\mathrm{I}_{\mathrm{D}} / \mathrm{I}_{\mathrm{G}}$, and La calculated according to [32], of as-received CNFs and $\mathrm{PP} / 5 \mathrm{wt}$ \% CNF composite.

\begin{tabular}{ccccccc}
\hline Sample & $\begin{array}{c}\omega_{G} \\
\left(\mathbf{c m}^{-1}\right)\end{array}$ & $\begin{array}{c}\text { FWHM }_{\mathbf{G}} \\
\left(\mathbf{c m}^{-\mathbf{1}}\right)\end{array}$ & $\begin{array}{c}\boldsymbol{\omega}_{\mathbf{D}} \\
\left(\mathbf{c m}^{-\mathbf{1}}\right)\end{array}$ & $\begin{array}{c}\mathbf{F W H M}_{\mathbf{D}} \\
\left(\mathbf{c m}^{-\mathbf{1}}\right)\end{array}$ & $\mathbf{I}_{\mathbf{D}} / \mathbf{I}_{\mathbf{G}}$ & $\mathbf{L}_{\mathbf{a}}(\mathbf{n m})$ \\
\hline $\mathrm{CNF}$ & 1580 & 90 & 1352 & 115 & 0.76 & 5.8 \\
$\mathrm{PP} / \mathrm{CNF}$ & 1587 & 50 & 1353 & 75 & 0.7 & 6.3 \\
\hline
\end{tabular}

The elemental composition of PP, as-received CNFs, and melt-mixed PP/CNF composite was analysed by XPS, and listed in Table 2. All samples contain mainly carbon and oxygen, as is evidenced by their survey XPS spectra (Figure 4). In addition, some inorganic impurities such as sulphur (S) ( $\sim .1 \%)$ in the as-received CNF powder, and silicon (Si) $(\sim 0.5 \%)$ in PP and the PP/CNF composite (Table 2$)$ were detected. In particular, the presence of sulphur in this type of CNFs has been previously observed, together with growth catalyst impurities such as iron [26]. The presence of Si in PP and the PP/CNF composite can be assigned to contaminations accumulated during the melt-mixing process. Moreover, the composition analysis of the neat CNFs revealed an amount of oxygen of $\sim 1.62 \%$, which increases up to $2.64 \%$ in the PP/CNF composite (Table 2 ).

Table 2. Chemical composition and surface atomic \% of PP, CNF and PP/5 wt. \% CNF composite.

\begin{tabular}{ccccc}
\hline Sample & O1s & C1s & S2p & Si2p \\
\hline PP & 2.0 & 97.5 & - & 0.5 \\
CNF & 1.6 & 98.2 & 0.1 & - \\
PP/CNF & 2.6 & 96.9 & - & 0.5 \\
\hline
\end{tabular}

A comparison of the deconvolution of $\mathrm{C} 1 \mathrm{~s}$ and $\mathrm{O} 1 \mathrm{~s}$ spectra for PP, neat $\mathrm{CNF}$ and the melt-mixed PP/CNF composite is presented in Figure 5. The C1s deconvolution of the neat PP shows a strong line at $\sim 285.8 \mathrm{eV}$ assigned to $\mathrm{C}-\mathrm{C}$ bonds, and another line at $286.5 \mathrm{eV}$ assigned to $\mathrm{C}-\mathrm{O}$ bonds (Figure 5e) [34]. In the case of the neat $\mathrm{CNFs}$, their $\mathrm{C} 1 \mathrm{~s}$ show a strong line at $\sim 284.4 \mathrm{eV}$ assigned to $\mathrm{C}-\mathrm{C}$ bonds, which together with the "satellite" peaks at $290.5 \mathrm{eV}$ represent $\mathrm{sp}^{2}$ hybridized carbon, an additional peak is observed at $285.2 \mathrm{eV}$ assigned to $\mathrm{C}-\mathrm{O}$ bonds (Figure $5 \mathrm{c}$ ) $[35,36]$. The $\mathrm{C} 1$ s deconvolution of $\mathrm{PP} / \mathrm{CNF}$ composites presents similar results as the neat $\mathrm{CNFs}$, though the $\mathrm{C}-\mathrm{C}$ and $\mathrm{C}-\mathrm{O}$ bonds are slightly shifted to $284.8 \mathrm{eV}$ and $285.3 \mathrm{eV}$, respectively. However, it is of note that the $\pi-\pi^{*}$ peaks did 
not appear in the C1s spectra of PP/CNF composites (Figure 5a), which can be explained by the high presence of PP. On the other hand, the O1s deconvolution of neat PP shows a strong line at $532.7 \mathrm{eV}$ (Figure 5f) assigned to $\mathrm{C}-\mathrm{O}$ bonds [37]. The O1s spectra in CNFs (Figure 5d) yielded asymmetric peaks at $531.6 \mathrm{eV}$ assigned to $\mathrm{C}=\mathrm{O}$ [38], and $533.2 \mathrm{eV}$ assigned to $\mathrm{C}-\mathrm{O}$ [39]. Interestingly, the O1s spectra of PP/CNF composites (Figure 5b) show only a peak at $532.2 \mathrm{eV}$, which can be associated to both $\mathrm{C}-\mathrm{O}$ and $\mathrm{C}=\mathrm{O}$ bonds.

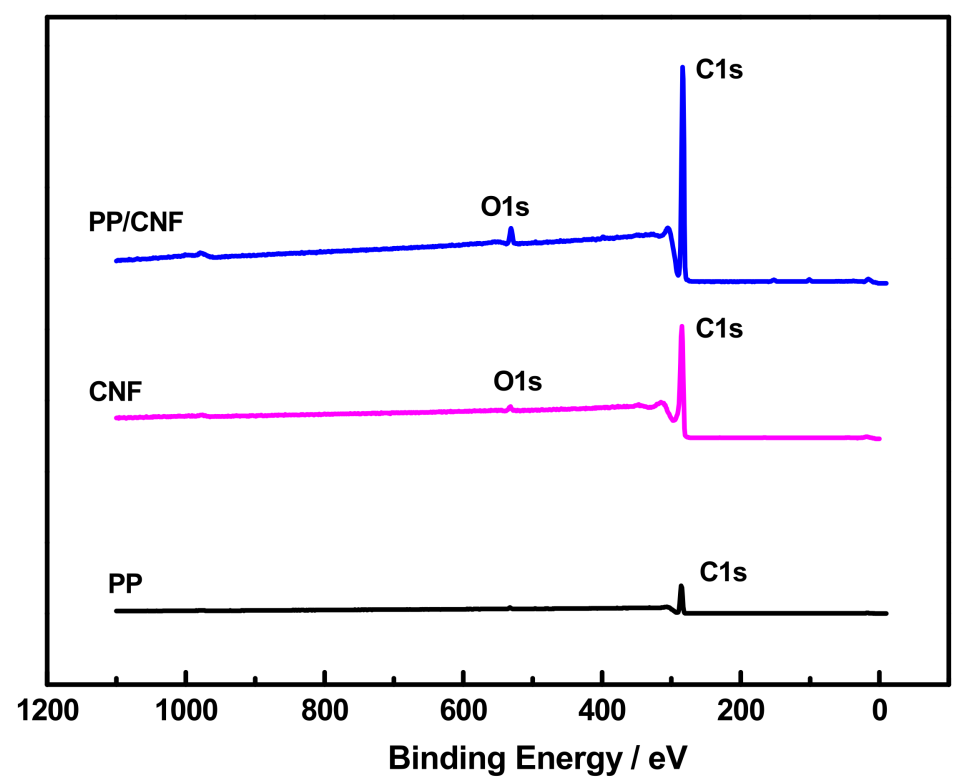

Figure 4. XPS survey spectra of PP, CNF powder, and PP/5 wt.\% CNF composite.
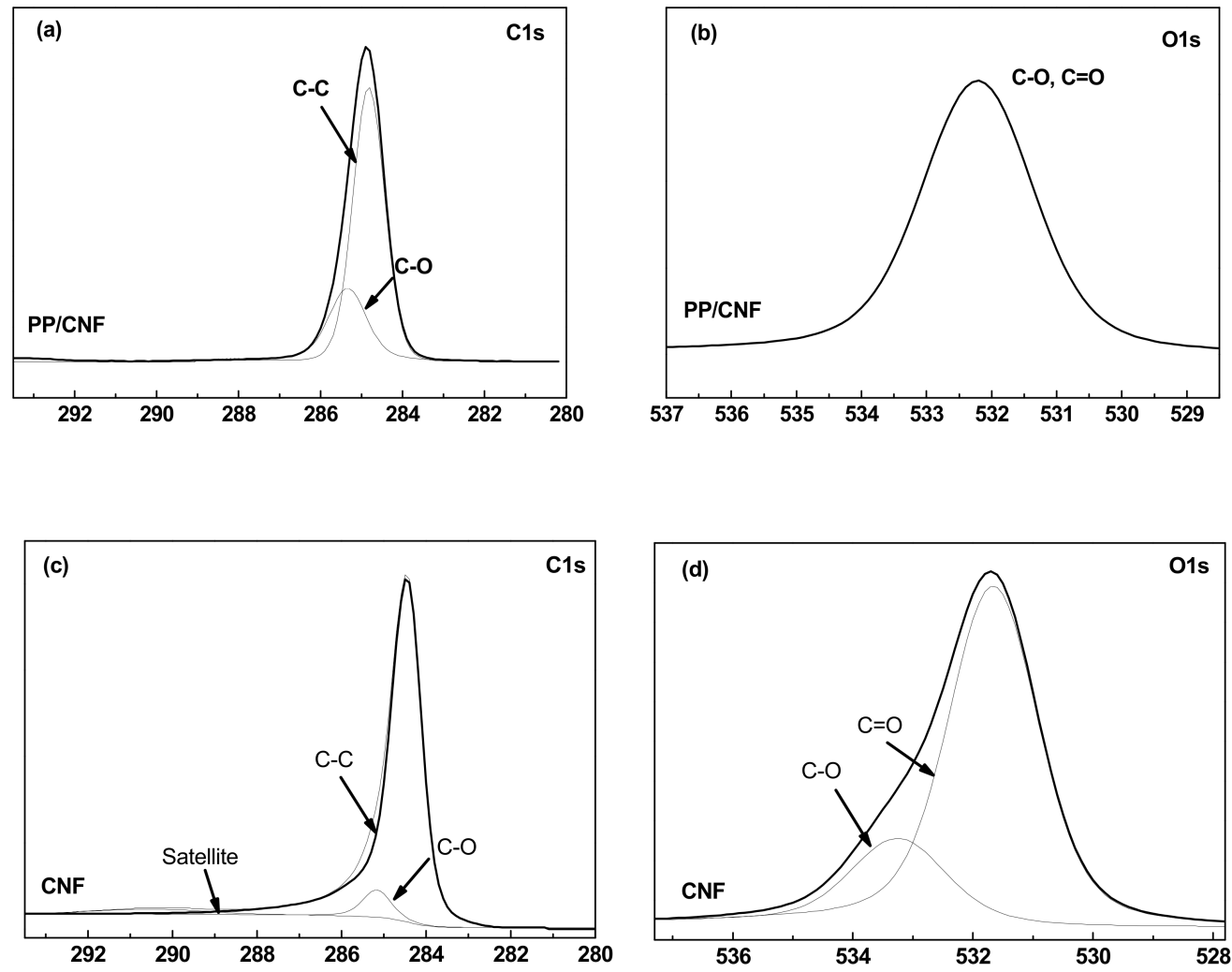

Figure 5. Cont. 

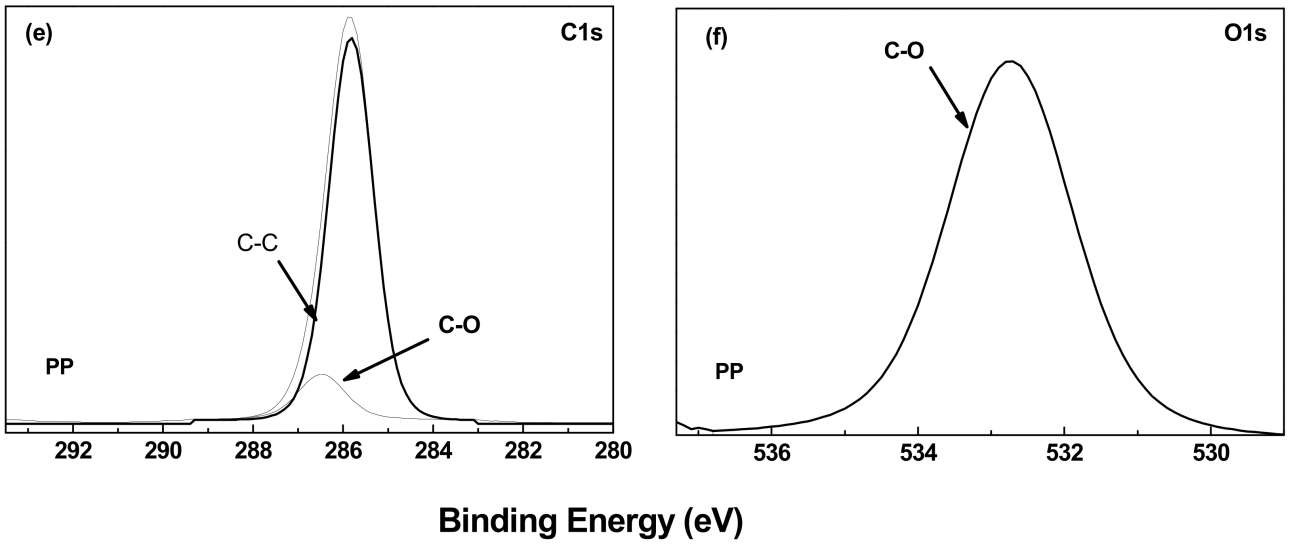

Figure 5. XPS deconvolution of $\mathrm{C} 1 \mathrm{~s}(\mathbf{a})$ and $\mathrm{O} 1 \mathrm{~s}(\mathbf{b})$ of PP/5 wt.\% CNF composite; $\mathrm{C} 1 \mathrm{~s}$ (c) and O1s (d) of CNFs; C1s (e), O1s (f) of PP.

\subsection{Thermoelectric Analysis}

The electrical conductivity of the CNF powder and the PP/CNF composite as functions of the measuring temperature are presented as squared symbols in Figure 6, whereas the exact values can be seen in Table 3. In particular, a value of $136.39 \pm 0.22 \mathrm{~S} \mathrm{~m}^{-1}$, equivalent to $\sim 7 \times 10^{-1} \mathrm{Ohm} \mathrm{cm}$, is measured for the $\mathrm{CNF}$ powder at $303.15 \mathrm{~K}\left(30{ }^{\circ} \mathrm{C}\right)$, which decreases up to $127.01 \pm 14.36 \mathrm{~S} \mathrm{~m}^{-1}$ at $373.15 \mathrm{~K}\left(100^{\circ} \mathrm{C}\right)$. The electrical resistivity at $30^{\circ} \mathrm{C}$ is significantly higher than the value of $4 \times 10^{-3} \mathrm{Ohm} \mathrm{cm}$ previously reported for individual Pyrograf ${ }^{\circledR}$ III CNFs [40]. This difference can be ascribed to the higher electrical resistivity, originated by higher contact resistances at the connection points of the nanofibres within the compressed CNF powder. Interestingly, the electrical conductivity of the here-used CNF grade is lower than the values of $\sim 320 \mathrm{~S} \mathrm{~m}^{-1}$ at $30^{\circ} \mathrm{C}$ reported for the Pyrograf ${ }^{\circledR} \mathrm{III} \mathrm{CNF}$ grade PR 24 LHT XT as previously reported [21]. This significant difference between the $\sigma$ of both CNF grades could be explained by the higher agglomerate sizes reported of the as-received PR 19 LHT XT CNFs, ranging from 100 to $200 \mu \mathrm{m}$ as compared to 10 to $100 \mu \mathrm{m}$ observed for the as-received PR 24 LHT XT CNFs [26]. In this respect, the higher ordered outer layers of the latter CNF grade (PR 24 LHT XT) together with the lower diameters of its outer layers could enhance not only the electron transport within and across their sidewalls, but also the electronic hopping between adjacent CNFs, thus explaining their higher $\sigma$ values. Notably, $\mathrm{d} \sigma / \mathrm{d} T<0$ is observed over the studied range of temperatures, which is in contrast to previous works reporting the temperature dependence electrical conductivity of SWCNT [41-43] and MWCNT mats [44]. The $\sigma(T)$ of the CNF powder has been described in this study by the 3D variable range hopping (VRH) model [41,45]:

$$
\sigma(T)=\sigma_{0} \exp \left[-\left(\frac{T_{C}}{T}\right)^{\frac{1}{4}}\right]
$$

where $\sigma_{0}$ is considered as the value of conductivity at an infinite temperature, while $T_{C}$ is the characteristic temperature that determines the thermally activated hopping among localized states at different energies. In particular, $T_{C}$ can be expressed as function of the energy barrier constant $\left(W_{D}\right)$ as $T_{C} \equiv \frac{\left|W_{D}\right|}{k}$, with $k$ as the Boltzmann's constant. A good agreement is observed for the CNF powder by fitting the Equation (1) with $\sigma_{0}=46.40 \mathrm{~S} \mathrm{~m}^{-1}$, $T_{C}=393.2 \mathrm{~K}$, and $W_{D}=-34 \mathrm{meV}$ (Figure 6). Interestingly, the value of $T_{C}$ is in the same order as some reported SWCNT mats $(250 \mathrm{~K})$ [43], though more recent works have reported $T_{C}$ values with one order of magnitude lower $(20 \mathrm{~K})$ for SWCNT mats tested in the $0-300 \mathrm{~K}$ interval [41,42]. Notably, the negative sign of $W_{D}$ can be explained by the presence of impurities such as the iron $(\mathrm{Fe})(1.19 \%)$ detected in another study by wavelength dispersive $X$-ray fluorescence (WDXRF) [26] and the oxygen (1.6\%) and sulphur $(0.1 \%)$ contents observed by XPS in this study. These impurities could originate a thermal-enhanced backscattering mechanism due to the presence of virtual bound-states, represented as sharp peaks near 
the $\mathrm{E}_{\mathrm{F}}$ in the density of states $[44,46]$. This is an unexpected phenomenon since the majority of work that evaluates the $\sigma(T)$ of CNT mats reports positive signs of $W_{D}[41,44]$. In comparative terms, the barrier energy value of the CNF powder $(34 \mathrm{meV})$ is in the middle between the activation energy reported for n-type graphitized carbon fibres $(60 \mathrm{meV})$ in the 250-750 K interval [47], and the activation energy reported for SWCNT mats doped with boron $(12.2 \mathrm{meV})$ in the $0-320 \mathrm{~K}$ range by using the Arrhenius approach [44].

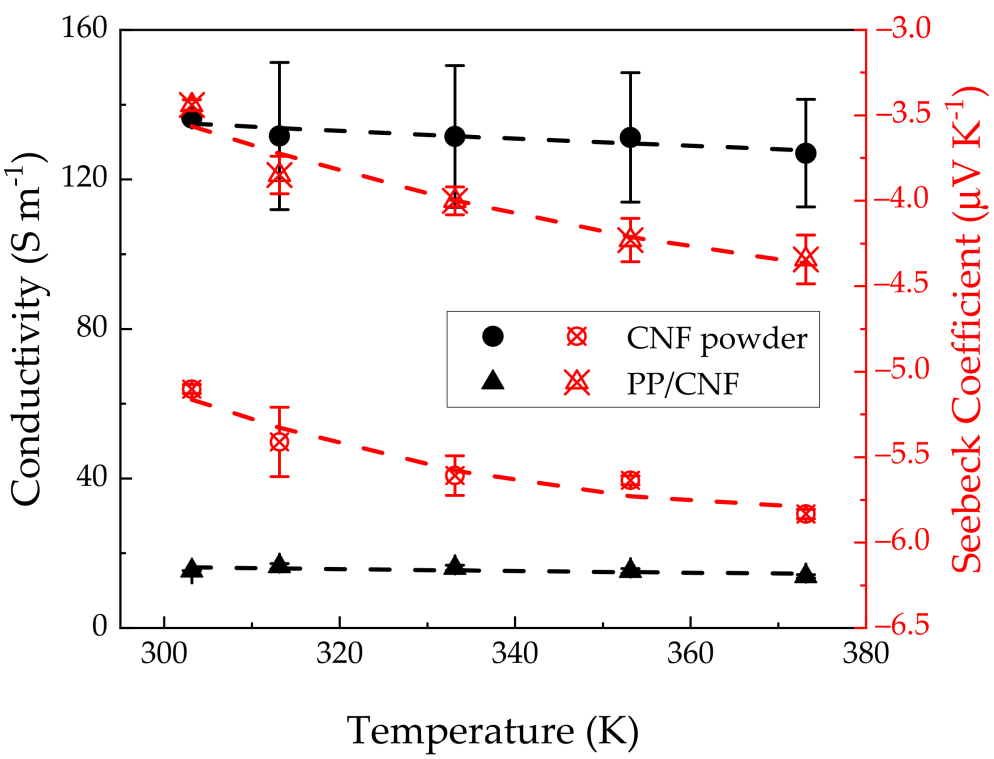

Figure 6. Electrical conductivity (squared symbols, black) and Seebeck coefficient (triangle symbols, red) as function of temperature of CNF powder and PP/5 wt.\% CNF composite. The black and red dash lines represent the fitting with Equation (1) and Equation (2), respectively.

Table 3. Thermoelectric properties of CNF powder and PP/5 wt.\% CNF composite as function of temperature.

\begin{tabular}{|c|c|c|c|c|c|c|c|c|}
\hline \multirow[b]{2}{*}{$\begin{array}{l}\text { Temperature } \\
\text { (K) }\end{array}$} & \multicolumn{3}{|c|}{ CNF Powder } & \multicolumn{5}{|c|}{$\mathrm{PP} / \mathrm{CNF}$} \\
\hline & $\sigma\left(\mathbf{S ~ m}^{-1}\right)$ & $S\left(\mu \mathrm{V} \mathrm{K}^{-1}\right)$ & $\underset{\left.\mathbf{m}^{-1} K^{-2}\right)}{P F}(\mu W$ & $\sigma\left(\mathrm{S} \mathrm{m}^{-1}\right)$ & $S\left(\mu \mathrm{V} \mathrm{K}^{-1}\right)$ & $\begin{array}{c}\mathrm{PF}(\mu W \\
\left.\mathbf{m}^{-1} \mathbf{K}^{-2}\right)\end{array}$ & $\begin{array}{c}k(W \\
\left.\mathbf{m}^{-1} \mathbf{K}^{-1}\right)\end{array}$ & $z T$ \\
\hline 303.15 & $136.39 \pm 0.22$ & $-5.10 \pm 0.03$ & $3.55 \times 10^{-3}$ & $15.36 \pm 0.01$ & $-3.44 \pm 0.03$ & $1.82 \times 10^{-4}$ & 0.25 & $2.20 \times 10^{-7}$ \\
\hline 313.15 & $131.51 \pm 19.70$ & $-5.41 \pm 0.20$ & $3.85 \times 10^{-3}$ & $16.54 \pm 0.70$ & $-3.85 \pm 0.11$ & $2.45 \times 10^{-4}$ & 0.25 & $3.07 \times 10^{-7}$ \\
\hline 333.15 & $131.48 \pm 18.95$ & $-5.61 \pm 0.12$ & $4.13 \times 10^{-3}$ & $16.07 \pm 0.72$ & $-4.00 \pm 0.08$ & $2.57 \times 10^{-4}$ & 0.24 & $3.57 \times 10^{-7}$ \\
\hline 353.15 & $131.21 \pm 17.33$ & $-5.64 \pm 0.03$ & $4.17 \times 10^{-3}$ & $15.26 \pm 0.64$ & $-4.23 \pm 0.13$ & $2.73 \times 10^{-4}$ & 0.24 & $4.09 \times 10^{-7}$ \\
\hline 373.15 & $127.01 \pm 14.36$ & $-5.83 \pm 0.03$ & $4.32 \times 10^{-3}$ & $13.86 \pm 0.45$ & $-4.34 \pm 0.14$ & $2.61 \times 10^{-4}$ & 0.22 & $4.39 \times 10^{-7}$ \\
\hline
\end{tabular}

Similar to the CNF powder, the PP/CNF composite shows a decrease in their conductivity $(\mathrm{d} \sigma / \mathrm{d} T<0)$ from $15.36 \pm 0.01 \mathrm{~S} \mathrm{~m}^{-1}$ at $303.15 \mathrm{~K}\left(30^{\circ} \mathrm{C}\right)$ to $13.86 \pm 0.45 \mathrm{~S} \mathrm{~m}^{-1}$ at $373.15 \mathrm{~K}\left(100^{\circ} \mathrm{C}\right)$ (Table 3$)$. It must be noted that the PP/CNF composite is above its electrical percolation threshold $\left(\phi_{c}\right)$. For the $\mathrm{PP} / 4 \mathrm{wt} . \% \mathrm{CNF}$ composite, a volume resistivity of around $10^{7} \mathrm{Ohm} \mathrm{cm}$ was measured which was too high for performing stable TE measurements. In an earlier study the $\phi_{c}$ was found to be between 1 and $2 \mathrm{wt} . \%$, when using the same mixtures, but compression moulded under slightly different conditions [48]. The $\sigma$ of $15.36 \mathrm{~S} \mathrm{~m}^{-1}$ for the PP/CNF composite is significantly lower than the $\sigma$ of the CNF powder $\left(136.39 \mathrm{~S} \mathrm{~m}^{-1}\right)$ at $303.15 \mathrm{~K}$. This significant difference, typically observed in melt-mixed polymer composites, can be attributed to the wrapping of polypropylene chains around the $\mathrm{CNFs}$, which increases the contact resistance between the adjacent CNFs, resulting in the rise of the CNF network resistivity [49]. Notably, the $\sigma$ of PP/CNF composites $\left(15.36 \mathrm{~S} \mathrm{~m}^{-1}\right)$ was lower than the $\sigma$ of melt-mixed PP composites with $5 \mathrm{wt}$.\% of the PR 24 LHT XT CNFs grade (49.5 S m$~_{-1}$ ) reported previously [21], which can be related to the structural differences and higher conductivities observed for the PR 24 LHT XT CNF powder. More- 
over, the $\sigma(T)$ for the PP/CNF composites has been also depicted by the 3D VRH model (Equation (1)), from which $\sigma_{0}=1.76 \mathrm{~S} \mathrm{~m}^{-1}, T_{C}=7.43 \times 10^{3} \mathrm{~K}$ and $W_{D}=-640$ meV have been obtained. Thereby, $\sigma_{0}$ is one order of magnitude lower than the $\sigma_{0}$ of the CNF powder due to the insulating nature of the matrix PP. Interestingly, a similar $\sigma_{0}$ of $1.75 \mathrm{~S} \mathrm{~m}^{-1}$ by using the Arrhenius equation has been reported for epoxy composites filled with $10 \mathrm{phr}$ of MWCNTs tested in the 303.15-433.15 K range [50]. However, the obtained $T_{C}$ resulted two orders of magnitude lower than the $T_{C}$ reported for epoxy composites filled with $35 \mathrm{phr}$ of carbon black $(\mathrm{CB})\left(6.19 \times 10^{5} \mathrm{~K}\right)$ tested in the range $303.15-453.15 \mathrm{~K}$ by using the 3D VRH [51]. This implies that, the thermally activated backscattering mechanism can again be responsible for the negative $W_{D}$ found in the PP/CNF composite. Notably, the $\mathrm{d} \sigma / \mathrm{d} T<0$ contrasts with the $\mathrm{d} \sigma / \mathrm{d} T>0$ (in the $0-300 \mathrm{~K}$ interval) reported in epoxy composites produced with exactly the same PR 19 LHT XT CNFs [52]. Furthermore, the absolute value of $W_{D}(0.640 \mathrm{eV})$ is consistent with the activation energy $(0.488 \mathrm{eV})$ obtained by using the Arrhenius approach for epoxy composites filled with 5 phr MWCNTs [50]. In view of these results, it is remarked that a statistical model such as VRH seems to provide a good first approach to understand the underlying transport mechanism behind the high degree of morphological disorder present in the materials studied in this work (as-received CNF powder and PP/CNF composite).

The triangle symbols in Figure 6 present the thermopower of the CNF powder and the $\mathrm{PP} / \mathrm{CNF}$ composite as a function of temperature. The n-type character of the CNF powders is found at all temperatures, and it contrasts to the findings of most as-produced CNTs that are p-type due to their oxygen doping with the environment [53]. In particular, the CNF powder presented an S-value of $-5.10 \pm 0.03 \mu \mathrm{V} \mathrm{K}^{-1}$ at $303.15 \mathrm{~K}\left(30{ }^{\circ} \mathrm{C}\right)$, which increases gradually (in absolute value) up to $-5.83 \pm 0.03 \mu \mathrm{V} \mathrm{K} \mathrm{K}^{-1}$ at $373.15 \mathrm{~K}\left(100{ }^{\circ} \mathrm{C}\right)$ (Table 3). Notably, that S-value $\left(-5.1 \mu \mathrm{V} \mathrm{K}{ }^{-1}\right)$ is slightly lower than the value of $-5.5 \pm 0.1 \mu \mathrm{V} \mathrm{K}^{-1}$ at $303.15 \mathrm{~K}$ reported for the Pyrograf ${ }^{\circledR}$ III CNF PR 24 LHT XT grade [21]. Moreover, the results are similar to the scarce negative $S$-values found in literature for free-standing MWCNT films grown by CVD at room temperature [54], and the $-6 \mu \mathrm{V} \mathrm{K}^{-1}$ reported for MWCNT buckypapers grown by CVD [55]. The $S(T)$ of the CNF powder can be depicted by the theoretical model proposed by Choi et al. for describing the nonlinear thermopower behaviour of doped MWCNT mats [44]:

$$
S(T)=b T+\frac{c T_{p}}{T^{2}} \frac{\exp \left(\frac{T_{P}}{T}\right)}{\left[\exp \left(\frac{T_{P}}{T}\right)+1\right]^{2}}
$$

In Equation (2), $b T$ represents the metallic (linear) term, $c$ is a constant, and $T_{p}=\left(E_{p}-E_{F}\right) / k$ where $k$ is the Boltzmann's constant, $E_{F}$ is the Fermi energy level, and $E_{P}$ is the energy corresponding to the sharply varying and localized states near $E_{F}$ in the density of states due to the contribution of impurities [44,46]. The best fit of the $S(T)$ with Equation (2) for the CNF powder (Figure 6) shows that the first term is positive with $b=5.50 \times 10^{-3} \mu \mathrm{V} \mathrm{K}^{-2}$, while the second term is negative with $c=-1.80 \times 10^{4} \mu \mathrm{V} \mathrm{K}$ and $T_{p}=993.21 \mathrm{~K}$, yielding a $E_{P}-E_{F}=0.086 \mathrm{eV}$ and an overall negative $S$ that gradually increases (in absolute value) with temperature. Thus, for instance at $303.15 \mathrm{~K}$, the metallic contribution yields $\sim+1.7 \mu \mathrm{V} \mathrm{K}-1$, and the second term is $\sim-6.8 \mu \mathrm{V} \mathrm{K} \mathrm{K}^{-1}$, whereas at $373.15 \mathrm{~K}$, the metallic contribution is $\sim+2 \mu \mathrm{V} \mathrm{K}^{-1}$ and the second term is $\sim-7.8 \mu \mathrm{V} \mathrm{K} \mathrm{K}^{-1}$.

The PP/CNF composite shows thermopowers from $-3.44 \pm 0.03 \mu \mathrm{V} \mathrm{K}^{-1}$ at $303.15 \mathrm{~K}$ to $-4.34 \pm 0.14 \mu \mathrm{V} \mathrm{K}^{-1}$ at $373.15 \mathrm{~K}$. The $S(T)$ of the PP/CNF composite is also fitted by Equation (2) with the best fit resulting in $b=1.55 \times 10^{-3} \mu \mathrm{V} \mathrm{K}^{-2}, c=-1.29 \times 10^{4} \mu \mathrm{V} \mathrm{K}$, $T_{p}=1083.9 \mathrm{~K}$ and $E_{P}-E_{F}=0.094 \mathrm{eV}$. Thus at $303.15 \mathrm{~K}$, the metallic contribution is $\sim+0.4 \mu \mathrm{V} \mathrm{K}^{-1}$, and the second term is $\sim-4.0 \mu \mathrm{V} \mathrm{K} \mathrm{K}^{-1}$, whereas at $373.15 \mathrm{~K}$, the metallic contribution is $\sim+0.6 \mu \mathrm{V} \mathrm{K}^{-1}$ and the second term is $\sim-5.0 \mu \mathrm{V} \mathrm{K}^{-1}$. Therefore, as in the case of the CNF powder, the overall sign of the thermopower in the PP/CNF composite is dominated by the resonances near the $E_{F}$ at the density of states (second term of Equation (2)) 
caused by impurities present in the CNF structure. It is observed by comparing the results at $303.15 \mathrm{~K}$ that the positive metallic contribution of the PP/CNF composite $\left(+0.4 \mu \mathrm{V} \mathrm{K}^{-1}\right)$ is $\sim 77 \%$ lower than that of the CNF powder $\left(+1.7 \mu \mathrm{V} \mathrm{K}^{-1}\right)$, and this difference is slightly reduced at $373.15 \mathrm{~K}(\sim 70 \%)$. This result can be explained as a consequence of the oxygen doping reduction in the CNFs caused by the presence of the insulating PP chains. Similarly, it is also of note that at $303.15 \mathrm{~K}$ the second term of Equation (2) is $41 \%$ lower in absolute value for the PP/CNF composite $(-4.0 \mu \mathrm{V} \mathrm{K}-1)$ than that of the CNF powder $\left(-6.8 \mu \mathrm{V} \mathrm{K}^{-1}\right)$. This change is again reduced at $373.15 \mathrm{~K}(\sim 36 \%)$. Thus, the presence of PP chains around the nanofibres seems to clearly affect the second term of Equation (2). In this respect, the slight electron transfer from the CNF outer layers towards the surrounding PP molecular chains [21] could explain the lower absolute values of the second term in Equation (2) found for the PP/CNF composite.

The power factor PF as function of temperature of the PP/CNF composite and CNF powder were calculated, and the results are shown in Table 3. At $303.15 \mathrm{~K}$, the CNF powder shows a PF of $3.5 \times 10^{-3} \mu \mathrm{W} \cdot \mathrm{m}^{-1} \cdot \mathrm{K}^{-2}$, whereas the PP/CNF composite achieves a PF of $1.8 \times 10^{-4} \mu \mathrm{W} \cdot \mathrm{m}^{-1} \cdot \mathrm{K}^{-2}$ (lower than the PF of $7.0 \times 10^{-4}$ obtained in PP/CNF composite with $5 \mathrm{wt} . \%$ of PR 24 LHT XT CNFs [21]). The PF increases in both materials at $373.15 \mathrm{~K}$ as a consequence of its proportionality to $S^{2}$. The CNF powder achieves a value of $4.3 \times 10^{-3} \mu \mathrm{W} \cdot \mathrm{m}^{-1} \cdot \mathrm{K}^{-2}$, whereas the PP/CNF composites achieves a PF of $2.6 \times 10^{-4} \mu \mathrm{W} \cdot \mathrm{m}^{-1} \cdot \mathrm{K}^{-2}$. For comparison, PF values of $\sim 10^{-1} \mu \mathrm{W} \cdot \mathrm{m}^{-1} \cdot \mathrm{K}^{-2}$ have been recently reported in a melt-mixed PP composite with $2 \mathrm{wt} . \%$ of p-type boron-doped SWCNTs [56].

The figure of merit $z T$ of the PP/CNF composite increases slightly from $2.2 \times 10^{-7}$ $\left(30^{\circ} \mathrm{C}\right)$ up to $4.4 \times 10^{-7}\left(100^{\circ} \mathrm{C}\right)$ due to the increasing PF and slightly decreasing thermal conductivity values (see Table 3 ). This zT value is lower compared to $4.8 \times 10^{-7}\left(30^{\circ} \mathrm{C}\right.$ ) obtained for PP $/ 5 \mathrm{wt} . \%$ PR 24 LHT XT CNFs [21]. It must be also noted that higher zT values ( 3.0 to $3.3 \times 10^{-5}$ at $40{ }^{\circ} \mathrm{C}$ ) were reported for PP composites filled with $2 \mathrm{wt} . \%$ SWCNT Tuball ${ }^{\mathrm{TM}}$ or $2 \mathrm{wt} . \%$ branched MWCNT CNS-PEG [14].

\section{Conclusions}

The electrical conductivity $(\sigma)$ and thermopower $(S)$ of as-received vapour grown carbon nanofibre (CNF) powder and its melt-mixed polypropylene composite with $5 \mathrm{wt} . \%$ of CNFs in the temperature range between $30^{\circ} \mathrm{C}$ and $100{ }^{\circ} \mathrm{C}$ have been analysed in this study. At $30^{\circ} \mathrm{C}$, the $\sigma, S$ and power factor (PF) of the as-received CNFs are $\sim 136 \mathrm{~S} \mathrm{~m}^{-1}$, $-5.1 \mu \mathrm{V} \mathrm{K}^{-1}$ and $3.5 \times 10^{-3} \mu \mathrm{W} \mathrm{m} \mathrm{m}^{-1} \mathrm{~K}^{-2}$, respectively. The PP/CNF composite, for its part, shows lower conductivities of $\sim 15 \mathrm{~S} \mathrm{~m}^{-1}$, and less negative S-values of $-3.4 \mu \mathrm{V} \mathrm{K}^{-1}$, which correspond to a PF of $1.8 \times 10^{-4} \mu \mathrm{W} \mathrm{m}^{-1} \mathrm{~K}^{-2}$ at $30^{\circ} \mathrm{C}$. Notably, the $\sigma(T)$ of both materials presents a $\mathrm{d} \sigma / \mathrm{d} T<0$ character, which is in contrast to the $\mathrm{d} \sigma / \mathrm{d} T>0$ generally found for CNT mats and can be perfectly fitted by the statistical 3D VRH model. As regards their $S$ (T), it follows the theoretical model proposed for describing the nonlinear thermopower of certain doped MWCNT mats. In particular, the $\mathrm{d} S / \mathrm{d} T>0$ behaviour observed in both samples has been physically interpreted by the presence of some impurities in the CNFs, which could produce sharp peaks close to the Fermi energy level $\left(E_{F}\right)$ in their density of states. In summary, this study gives new insights in the origin of the negative and air stable $\mathrm{S}$-values found in some commercial grades of as-received vapour grown carbon nanofibres and their melt-mixed composites with insulating polymers.

Author Contributions: All authors of this manuscript contributed to development of this work. Conceptualization A.J.P.; methodology, A.J.P., B.K., M.F.C. and E.M.; resources, A.M.R. and P.P.; data curation A.J.P.; writing-original draft preparation, A.J.P.; writing-review and editing, A.J.P., B.K., E.M. and P.P.; supervision, B.K., E.M. and P.P.; project administration, A.M.R.; funding acquisition, A.M.R. All authors have read and agreed to the published version of the manuscript. 
Funding: Antonio J. Paleo gratefully acknowledges support from FCT-Foundation for Science and Technology by the "plurianual" 2020-2023 Project UIDB/00264/2020. E. Muñoz acknowledges support from Fondecyt grant number 1190361 and from ANID PIA Anillo ACT/192023.

Institutional Review Board Statement: Not applicable.

Informed Consent Statement: Not applicable.

Data Availability Statement: The authors confirm that the data supporting the findings of this study are available within the article.

Acknowledgments: The authors would like to thank the collaborators of the IPF research technology department for their support in designing and building the thermoelectric equipment including the software and Manuela Heber (IPF) for taking the SEM images. The authors gratefully acknowledge the support of $\mathrm{O}$. Bondarchuck with the XPS analysis.

Conflicts of Interest: The authors declare no conflict of interest.

\section{References}

1. Nandihalli, N.; Liu, C.-J.; Mori, T. Polymer based thermoelectric nanocomposite materials and devices: Fabrication and characteristics. Nano Energy 2020, 78, 105186. [CrossRef]

2. $\quad$ Rowe, D.M. CRC Handbook of Thermoelectrics; CRC Press: Boca Raton, FL, USA, 1995.

3. Blackburn, J.L.; Ferguson, A.J.; Cho, C.; Grunlan, J.C. Carbon-Nanotube-Based Thermoelectric Materials and Devices. Adv. Mater. 2018, 30, 1704386. [CrossRef] [PubMed]

4. Vineis, C.J.; Shakouri, A.; Majumdar, A.; Kanatzidis, M.G. Nanostructured Thermoelectrics: Big Efficiency Gains from Small Features. Adv. Mater. 2010, 22, 3970-3980. [CrossRef] [PubMed]

5. Tan, G.; Zhao, L.-D.; Kanatzidis, M.G. Rationally Designing High-Performance Bulk Thermoelectric Materials. Chem. Rev. 2016, 116, 12123-12149. [CrossRef]

6. Han, S.; Chen, S.; Jiao, F. Insulating polymers for flexible thermoelectric composites: A multi-perspective review. Compos. Commun. 2021, 28, 100914. [CrossRef]

7. Baghdadi, N.; Zoromba, M.S.; Abdel-Aziz, M.H.; Al-Hossainy, A.F.; Bassyouni, M.; Salah, N. One-Dimensional Nanocomposites Based on Polypyrrole-Carbon Nanotubes and Their Thermoelectric Performance. Polymers 2021, 13, 278. [CrossRef]

8. Du, Y.; Cai, K.F.; Chen, S.; Cizek, P.; Lin, T. Facile Preparation and Thermoelectric Properties of $\mathrm{Bi}_{2} \mathrm{Te}_{3} \mathrm{Based} \mathrm{Alloy}$ Nanosheet/PEDOT:PSS Composite Films. ACS Appl. Mater. Interfaces 2014, 6, 5735-5743. [CrossRef]

9. He, M.; Ge, J.; Lin, Z.; Feng, X.; Wang, X.; Lu, H.; Yang, Y.; Qiu, F. Thermopower enhancement in conducting polymer nanocomposites via carrier energy scattering at the organic-inorganic semiconductor interface. Energy Environ. Sci. 2012, 5, 8351-8358. [CrossRef]

10. Bitenieks, J.; Buks, K.; Merijs-Meri, R.; Andzane, J.; Ivanova, T.; Bugovecka, L.; Voikiva, V.; Zicans, J.; Erts, D. Flexible N-Type Thermoelectric Composites Based on Non-Conductive Polymer with Innovative $\mathrm{Bi}_{2} \mathrm{Se}_{3}-\mathrm{CNT}$ Hybrid Nanostructured Filler. Polymers 2021, 13, 4264. [CrossRef]

11. Luo, J.; Cerretti, G.; Krause, B.; Zhang, L.; Otto, T.; Jenschke, W.; Ullrich, M.; Tremel, W.; Voit, B.; Pötschke, P. Polypropylene-based melt mixed composites with singlewalled carbon nanotubes for thermoelectric applications: Switching from p-type to n-type by the addition of polyethylene glycol. Polymer 2017, 108, 513-520. [CrossRef]

12. Zhang, Y.; Zhang, Q.; Chen, G. Carbon and carbon composites for thermoelectric applications. Carbon Energy 2020, 2, 408-436. [CrossRef]

13. Massetti, M.; Jiao, F.; Ferguson, A.J.; Zhao, D.; Wijeratne, K.; Würger, A.; Blackburn, J.L.; Crispin, X.; Fabiano, S. Unconventional Thermoelectric Materials for Energy Harvesting and Sensing Applications. Chem. Rev. 2021, 20, 12465-12547. [CrossRef]

14. Krause, B.; Barbier, C.; Levente, J.; Klaus, M.; Pötschke, P. Screening of Different Carbon Nanotubes in Melt-Mixed Polymer Composites with Different Polymer Matrices for Their Thermoelectrical Properties. J. Compos. Sci. 2019, 3, 106. [CrossRef]

15. Krause, B.; Konidakis, I.; Arjmand, M.; Sundararaj, U.; Fuge, R.; Liebscher, M.; Hampel, S.; Klaus, M.; Serpetzoglou, E.; Stratakis, E.; et al. Nitrogen-Doped Carbon Nanotube/Polypropylene Composites with Negative Seebeck Coefficient. J. Compos. Sci. 2020, 4, 14. [CrossRef]

16. Kang, I.; Heung, Y.Y.; Kim, J.H.; Lee, J.W.; Gollapudi, R.; Subramaniam, S.; Narasimhadevara, S.; Hurd, D.; Kirikera, G.R.; Shanov, V.; et al. Introduction to carbon nanotube and nanofiber smart materials. Compos. Part B Eng. 2006, 37, 382-394. [CrossRef]

17. Endo, M.; Tamagawa, I.; Koyama, T. Thermoelectric Power of Carbon Fibers Prepared from Benzene. Jpn. J. Appl. Phys. 1977, 16, 1771-1774. [CrossRef]

18. Heremans, J.; Beetz, C.P. Thermal conductivity and thermopower of vapor-grown graphite fibers. Phys. Rev. B 1985, 32, 1981-1986. [CrossRef] [PubMed]

19. Stokes, K.L.; Tritt, T.M.; Fuller-Mora, W.W.; Ehrlich, A.C.; Jacobsen, R.L. Electronic transport properties of highly conducting vapor-grown carbon fiber composites. In Proceedings of the Fifteenth International Conference on Thermoelectrics. Proceedings ICT '96, Pasadena, CA, USA, 26-29 March 1996; pp. 164-167. [CrossRef] 
20. Brownlie, L.; Shapter, J. Advances in carbon nanotube n-type doping: Methods, analysis and applications. Carbon 2018, 126, 257-270. [CrossRef]

21. Paleo, A.J.; Krause, B.; Cerqueira, M.F.; Melle-Franco, M.; Pötschke, P.; Rocha, A.M. Thermoelectric properties of polypropylene carbon nanofiber melt-mixed composites: Exploring the role of polymer on their Seebeck coefficient. Polym. J. 2021, 53, 1145-1152. [CrossRef]

22. Paleo, A.J.; Vieira, E.M.F.; Wan, K.; Bondarchuk, O.; Cerqueira, M.F.; Goncalves, L.M.; Bilotti, E.; Alpuim, P.; Rocha, A.M. Negative thermoelectric power of melt mixed vapor grown carbon nanofiber polypropylene composites. Carbon 2019, 150, $408-416$. [CrossRef]

23. Paleo, A.J.; Sencadas, V.; Van Hattum, F.W.J.; Lanceros-Méndez, S.; Ares, A. Carbon nanofiber type and content dependence of the physical properties of carbon nanofiber reinforced polypropylene composites. Polym. Eng. Sci. 2014, 54, 117-128. [CrossRef]

24. Jenschke, W.; Ullrich, M.; Krause, B.; Pötschke, P. Messanlage zur Untersuchung des Seebeck-Effektes in Polymermaterialien Measuring apparatus for study of Seebeck effect in polymer materials. Tech. Mess. 2020, 87, 495-503. [CrossRef]

25. Gnanaseelan, M.; Chen, Y.; Luo, J.; Krause, B.; Pionteck, J.; Pötschke, P.; Qi, H. Cellulose-carbon nanotube composite aerogels as novel thermoelectric materials. Compos. Sci. Technol. 2018, 163, 133-140. [CrossRef]

26. Tessonnier, J.P.; Rosenthal, D.; Hansen, T.W.; Hess, C.; Schuster, M.E.; Blume, R.; Girgsdies, F.; Pfänder, N.; Timpe, O.; Su, D.S.; et al. Analysis of the structure and chemical properties of some commercial carbon nanostructures. Carbon 2009, 47, 1779-1798. [CrossRef]

27. Nielsen, A.S.; Pyrz, R. A Raman study into the effect of transcrystallisation on thermal stresses in embedded single fibres. J. Mater. Sci. 2003, 38, 597-601. [CrossRef]

28. Snyder, R.G.; Schachtschneider, J.H. Valence force calculation of the vibrational spectra of crystalline isotactic polypropylene and some deuterated polypropylenes. Spectrochim. Acta 1964, 20, 853-869. [CrossRef]

29. Lehman, J.H.; Terrones, M.; Mansfield, E.; Hurst, K.E.; Meunier, V. Evaluating the characteristics of multiwall carbon nanotubes. Carbon 2011, 49, 2581-2602. [CrossRef]

30. Wang, Y.; Alsmeyer, D.C.; McCreery, R.L. Raman Spectroscopy of Carbon Materials: Structural Basis of Observed Spectra. Chem. Mater. 1990, 2, 557-563. [CrossRef]

31. Chipara, M.; Villarreal, J.R.; Chipara, M.D.; Lozano, K.; Chipara, A.C.; Sellmyer, D.J. Spectroscopic investigations on polypropylene-carbon nanofiber composites. I. Raman and electron spin resonance spectroscopy. J. Polym. Sci. Part B Polym. Phys. 2009, 47, 1644-1652. [CrossRef]

32. Knight, D.S.; White, W.B. Characterization of diamond films by Raman spectroscopy. J. Mater. Res. 1989, 4, 385-393. [CrossRef]

33. Ferrari, A.; Robertson, J. Interpretation of Raman spectra of disordered and amorphous carbon. Phys. Rev. B-Condens. Matter Mater. Phys. 2000, 61, 14095-14107. [CrossRef]

34. Chiang, M.H.; Liao, K.C.; Lin, I.M.; Lu, C.C.; Huang, H.Y.; Kuo, C.L.; Wu, J.S. Modification of hydrophilic property of polypropylene films by a parallel-plate nitrogen-based dielectric barrier discharge jet. IEEE Trans. Plasma Sci. 2010, 38, 1489-1498. [CrossRef]

35. Klein, K.L.; Melechko, A.V.; McKnight, T.E.; Retterer, S.T.; Rack, P.D.; Fowlkes, J.D.; Joy, D.C.; Simpson, M.L. Surface characterization and functionalization of carbon nanofibers. J. Appl. Phys. 2008, 103, 3. [CrossRef]

36. Zhou, J.H.; Sui, Z.J.; Zhu, J.; Li, P.; Chen, D.; Dai, Y.C.; Yuan, W.K. Characterization of surface oxygen complexes on carbon nanofibers by TPD, XPS and FT-IR. Carbon 2007, 45, 785-796. [CrossRef]

37. Kim, H.I.; Kim, S.S. Plasma treatment of polypropylene and polysulfone supports for thin film composite reverse osmosis membrane. J. Membr. Sci. 2006, 286, 193-201. [CrossRef]

38. Cuervo, M.R.; Asedegbega-Nieto, E.; Díaz, E.; Vega, A.; Ordóñez, S.; Castillejos-López, E.; Rodríguez-Ramos, I. Effect of carbon nanofiber functionalization on the adsorption properties of volatile organic compounds. J. Chromatogr. A 2008, 1188, 264-273. [CrossRef]

39. Zhong, R.S.; Qin, Y.H.; Niu, D.F.; Zhang, X.S.; Zhou, X.G.; Sun, S.G.; Yuan, W.K. Effect of carbon nanofiber surface groups on oxygen reduction reaction of supported Pt electrocatalyst. Electrochim. Acta 2013, 89, 157-162. [CrossRef]

40. Al-Saleh, M.H.; Sundararaj, U. A review of vapor grown carbon nanofiber/polymer conductive composites. Carbon 2009, 47, 2-22. [CrossRef]

41. Hewitt, C.A.; Kaiser, A.B.; Roth, S.; Craps, M.; Czerw, R.; Carroll, D.L. Varying the concentration of single walled carbon nanotubes in thin film polymer composites, and its effect on thermoelectric power. Appl. Phys. Lett. 2011, 98. [CrossRef]

42. Kymakis, E.; Amaratunga, G.A.J. Electrical properties of single-wall carbon nanotube-polymer composite films. J. Appl. Phys. 2006, 99, 084302. [CrossRef]

43. Fuhrer, M.S.; Holmes, W.; Richards, P.L.; Delaney, P.; Louie, S.G.; Zettl, A. Nonlinear transport and localization in single-walled carbon nanotubes. Synth. Met. 1999, 103, 2529-2532. [CrossRef]

44. Choi, Y.M.; Lee, D.S.; Czerw, R.; Chiu, P.W.; Grobert, N.; Terrones, M.; Reyes-Reyes, M.; Terrones, H.; Charlier, J.C.; Ajayan, P.M.; et al. Nonlinear behavior in the thermopower of doped carbon nanotubes due to strong, localized states. Nano Lett. 2003, 3, 839-842. [CrossRef]

45. Mott, N.F. Conduction in glasses containing transition metal ions. J. Non-Cryst. Solids 1968, 1, 1-17. [CrossRef]

46. Mahan, G.D. Impurity resonances in carbon nanotubes. Phys. Rev. B-Condens. Matter Mater. Phys. 2004, 69, 125407. [CrossRef]

47. Ivanov, D.K.; Ivanov, K.G.; Uryupin, O.N. Resistance and thermoelectric power of carbon fibers upon changing the conductivity type. Semiconductors 2017, 51, 834-835. [CrossRef] 
48. Paleo, A.J.; Van Hattum, F.W.J.; Pereira, J.; Rocha, J.G.; Silva, J.; Sencadas, V.; Lanceros-Méndez, S. The piezoresistive effect in polypropylene-carbon nanofibre composites obtained by shear extrusion. Smart Mater. Struct. 2010, 19, 065013. [CrossRef]

49. Li, C.; Thostenson, E.T.; Chou, T.W. Dominant role of tunneling resistance in the electrical conductivity of carbon nanotube-based composites. Appl. Phys. Lett. 2007, 91, 223114. [CrossRef]

50. Stavropoulos, S.G.; Sanida, A.; Psarras, G.C. A comparative study on the electrical properties of different forms of carbon allotropes-Epoxy nanocomposites. Express Polym. Lett. 2020, 14, 477-490. [CrossRef]

51. Psarras, G.C. Charge transport properties in carbon black/polymer composites. J. Polym. Sci. Part B Polym. Phys. 2007, 45, 2535-2545. [CrossRef]

52. Cardoso, P.; Silva, J.; Agostinho Moreira, J.; Klosterman, D.; Van Hattum, F.W.J.; Simoes, R.; Lanceros-Mendez, S. Temperature dependence of the electrical conductivity of vapor grown carbon nanofiber/epoxy composites with different filler dispersion levels. Phys. Lett. Sect. A Gen. At. Solid State Phys. 2012, 376, 3290-3294. [CrossRef]

53. Collins, P.G.; Bradley, K.; Ishigami, M.; Zettl, A. Extreme Oxygen Sensitivity of Electronic Properties of Carbon Nanotubes. Science 2000, 287, 1801-1804. [CrossRef] [PubMed]

54. Kumanek, B.; Stando, G.; Wróbel, P.S.; Janas, D. Impact of synthesis parameters of multi-walled carbon nanotubes on their thermoelectric properties. Materials 2019, 12, 3567. [CrossRef]

55. Hewitt, C.A.; Kaiser, A.B.; Craps, M.; Czerw, R.; Carroll, D.L. Negative thermoelectric power from large diameter multiwalled carbon nanotubes grown at high chemical vapor deposition temperatures. J. Appl. Phys. 2013, 114, 083701. [CrossRef]

56. Krause, B.; Bezugly, V.; Khavrus, V.; Ye, L.; Cuniberti, G.; Pötschke, P. Boron Doping of SWCNTs as a Way to Enhance the Thermoelectric Properties of Melt-Mixed Polypropylene/SWCNT Composites. Energies 2020, 13, 394. [CrossRef] 